\title{
(HIPER)PROTEÇÃO CONTRATUAL DO CONSUMIDOR: CONSOLIDAÇÃO DA DEFESA DOS CONSUMIDORES HIPERVULNERÁVEIS NO DIREITO BRASILEIRO
}

\section{CONTRACTUAL CONSUMER (HYPER)PROTECTION: CONSOLIDATION OF DEFENSE HYPERVULNERABLE CONSUMERS IN BRAZILIAN LAW}

${ }^{1}$ Aldo Cesar Filgueiras Gaudencio

\begin{abstract}
RESUMO
O estudo que se apresenta consiste na análise da vulnerabilidade dos consumidores frente às empresas nas relações contratuais estabelecidas para aquisição de produtos ou serviços. A proteção é mais invocada quando essa fragilidade inerente ao consumidor sofre influência de fatores relacionados à idade, enfermidade ou credulidade, dentre outros. Com efeito, o legislador e a jurisprudência precisam atentar para a real necessidade de uma maior proteção desse sujeito contratual "especialmente vulnerável", de modo a tentar restabelecer este equilíbrio negocial.
\end{abstract}

Palavras-chave: Proteção contratual, Consumidor, Vulnerável, Hipervulnerável

\begin{abstract}
The present study aims to be a analysis of the vulnerability of consumers faced wit companies in contractual relations established to purchase products or services. The protection is even more invoked when this inherent consumer's fragility is influenced b factors related to either age or infirmity or credulity, among others. Indeed, the legislato the jurisprudence must pay attention to a real need for greater protection on behalf of tha "specially vulnerable" contractual subject in order to restore the contractual balance.
\end{abstract}

Keywords: Contractual protection, Consumer, Vulnerable, Hypervulnerable

\footnotetext{
${ }^{1}$ Doutor em Direito Civil pela Universidade de Coimbra - UC, Lisboa (Portugal).

E-mail: aldogaudencio@yahoo.com.br
} 


\section{Introdução}

O direito sempre protegeu os mais fracos (CORDEIRO, 2005). Ao longo dos séculos, os ordenamentos jurídicos, desde os mais primitivos até os mais modernos, compreendiam à necessidade de proteção das pessoas em situação de desvantagem. Claramente, com o perpassar dos anos, o direito altera os seus mecanismos de tutela dos desfavorecidos em concomitância com os valores sociais vigentes, e o direito privado também imbuiu-se desta vertente jurídica de enxergar e salvaguardar os mais fracos (FILOMENO, 2010).

A história mostra que desde a antiguidade, a normatividade de caráter civil e comercial aponta algumas medidas de proteção dos mais frágeis ou vulneráveis que podem configurar uma espécie de defesa indireta aos compradores (hoje, por definição, consumidor ${ }^{1}$ ) (LORENZZETTI apud ZANCHET, 2005).

Desta maneira, a vulnerabilidade da pessoa deixou de ser algo meramente relacionado ao seu próprio comportamento e tornou-se um instrumento jurídico justificador de medidas de proteção em ocasiões de latente desequilíbrio - neste caso, o desequilíbrio nas relações entre particulares (MARQUES, 2014).

Na lei n. ${ }^{\circ} 8078 / 90$, especificamente na relação de princípios que baseiam a política nacional de defesa do consumidor, acreditamos que, mesmo não havendo hierarquia entre princípios, não por um acaso “o reconhecimento da vulnerabilidade do consumidor no mercado de consumo" está presente na posição primeira dos princípios.

A vulnerabilidade ou fragilidade dos consumidores nas relações contratuais diversas estabelecidas constantemente no mercado é elemento central para a justificava do envolvimento social e Estatal na defesa destes.

Para defendê-los fez-se necessário reconhecer a vulnerabilidade destes frente a diversa gama de fornecedores de produtos e serviços. E, ademais, a proteção dos consumidores parte também da ideia de se tratar o consumidor como um agente econômico

\footnotetext{
${ }^{1}$ Neste estudo, o autor buscou mostrar que a idéia da vulnerabilidade pode ter origem na Roma antiga, e que esta ideia tem, como ponto de partida, a interpretação em favor do devedor que evoluiu até chegar ao favor debilis em benefício do consumidor.
} 
(PASQUALOTTO, 2011) e o consumo sempre foi um conceito de economia ${ }^{2}$, porque a preocupação desses é um dos objetivos dessa ciência.

Para além dessa análise, identificamos grupos de consumidores que, por fatores ou condições pessoais sofrem maior prejuízo na liberdade de escolha e decisão nos contratos pactuados com empresas. Assim, vimos à necessidade analisar não apenas a vulnerabilidade, mas, também, esta "variação" da vulnerabilidade considerada a partir de alguns fatores como a idade, a doença, a credulidade, dentre outros, que agravam ou aumentam a sua já reconhecida condição de consumidor vulnerável. A este aumento da vulnerabilidade os autores e a jurisprudência no Brasil nomearam de hipervulnerabilidade ou vulnerabilidade agravada, tendo sido consolidado e ampliado na jurisprudência.

Ao identificar esta "especial vulnerabilidade" passamos a questionar: Qual o fundamento de uma "especial vulnerabilidade" - ou hipervulneráveis ou particularmente vulneráveis - dentro de uma sistemática de protecção dos consumidores? Existem, ou caso não existam, deve haver normas específicas para estes grupos especialmente vulneráveis? Tratase de uma nova categoria jurídica dentro do direito do consumidor?

Por fim, as indagações acima expostas são construção do raciocínio a ser desenvolvido neste trabalho, que tem como questão central buscar a análise do tratamento da vulnerabilidade e da "especial vulnerabilidade" no sistema de proteção dos consumidores ndo Brasil, os seus fundamentos, a sua previsão legal e a sua interpretação através da jurisprudência.

\section{A vulnerabilidade do consumidor}

Vê-se que o legislador brasileiro admite a vulnerabilidade como uma presunção absoluta ao admitir que todo consumidor é vulnerável, sem exceção ou restrição. Além disso, determina que o Estado deve reconhecer a vulnerabilidade do consumidor, ou seja, invoca o Estado a proteger o consumidor, de acordo com o dispositivo do artigo $5^{\circ}$, XXXII. Ademais, este reconhecimento estatal repercute no mercado que deve ser regulado, sendo-lhe imposto parâmetros ou medidas para a atividade econômica em defesa do consumidor, conforme previsão do seu artigo 170, inciso V (NUNES, 2012).

\footnotetext{
${ }^{2}$ Entendemos que, se os direitos dos consumidores alcançam o status de área autónoma do direito, ele não será um conceito só da economia.
} 
A Constituição Federal de 1988 reconhece a vulnerabilidade, que deve ser, portanto, tratada pelo legislador infraconstitucional de maneira diferencial para buscar a aplicação da igualdade nas relações contratuais em busca de uma igualdade material ${ }^{3}$. Conforme abordagem anterior a este tema, o princípio da vulnerabilidade está diretamente relacionado com outro princípio que lhe é pressuposto, o da igualdade. Aquele que é vulnerável, necessariamente se encontra em situação desigual, assim, podemos afirmar que o princípio da vulnerabilidade é subprincípio, derivado do princípio constitucional da igualdade expresso no caput do art. $5^{\circ}$ da Constituição Federal de 1988.

A Lei $n .^{\circ} 8.078 / 90$ identifica a vulnerabilidade no princípio da política nacional de proteção e de defesa do consumidor, ao prever no artigo $4^{\circ}$ que o Estado "deve então reconhecer a vulnerabilidade do consumidor no mercado" (MORAES, 2009, p. 125). O CDC prevê a vulnerabilidade como princípio geral, e linha filosófica, na qual toda e qualquer norma protetora do consumidor terá como base esta perspectiva. Destarte, a vulnerabilidade é o início de qualquer discussão sobre a defesa do consumidor, por isso, qualquer medida protetiva já parte desta premissa (TARTUCE e NEVES, 2012).

A vulnerabilidade do consumidor é presumida, sendo em certa medida o próprio fundamento da legislação de defesa do consumidor no Brasil (OLIVEIRA, 2009), logo é um princípio estruturante de seu sistema, do qual as normas decorrentes emergiam deste princípio (CAVALIERI FILHO, 2011), sendo desnecessária a sua caracterização em decorrência de uma circunstância ou aspecto especial (GIONCOLI e ARAÚJO JÚNIOR, 2012). Trata-se da quebra do paradigma contratual clássico ao se admitir que um dos lados da relação de consumo, o consumidor, é vulnerável frente ao díspare poder negocial na relação contratual que detém o fornecedor.

No âmbito de uma disciplina contratual cuja própria razão de ser consiste na "vulnerabilidade" do consumidor (art. 4, I do CDC), deixa de fazer sentido ignoraremse as características dos contratantes que determinem a sua melhor ou pior condição de barganha contratual. Um sistema de proteção e defesa fundado sobre a premissa de que é justo que o contratante vulnerável seja legalmente fortalecido frente à disparidade de poder negocial que a distância do outro contratante, constitui, sem dúvida, uma quebra da unidade e do formalismo da teoria contratual clássica. (NEGREIROS, 2002, p. 305).

3 A Constituição Federal de 1988 reconhece a vulnerabilidade e procura realizar a isonomia garantida pela própria Constituição no seu artigo $5^{\circ}$. 
A doutrina tradicionalmente aponta a existência de modalidades de vulnerabilidade (MIRAGEM, 2015). A vulnerabilidade técnica está direcionada na ideia de ausência de conhecimento técnico específico acerca do produto ou serviço objeto de consumo; a vulnerabilidade jurídica está determinada pela falta de conhecimento jurídico, contábil ou econômico e de seus reflexos na relação de consumo; e a vulnerabilidade socioeconômica está delimitada por situações em que a insuficiência econômica, física ou até mesmo psicológica do consumidor o coloca em pé de desigualdade frente ao fornecedor (BENJAMIM; MARQUES; BESSA, 2008).

Alguns doutrinadores incluem outras modalidades de vulnerabilidade, por exemplo, a vulnerabilidade informacional, que diz respeito aos dados insuficientes sobre o produto ou serviço capazes de influenciar no processo decisório de compra (MARQUES, 2014). Admite a doutrina outras espécies, i.e., a vulnerabilidade política ou legislativa, a vulnerabilidade biológica ou psíquica e a vulnerabilidade ambiental. No caso da vulnerabilidade política, identifica a ausência ou debilidade de poder do consumidor em relação ao lobby dos fornecedores nas casas legislativas. Já a vulnerabilidade biológica identifica-se como sendo a que caracteriza o consumidor diante das modernas técnicas de maketing adotadas pelos fornecedores e que repercutem na esfera da escolha livre do consumidor. Ainda, a vulnerabilidade ambiental, como sendo aquela que apresenta ao consumidor vantagens, mas na verdade são grandes riscos ao meio ambiente e, indiretamente, o consumidor em sua vida, saúde e segurança (MORAES, 2009).

\subsection{Diferença entre hipossuficiência e vulnerabilidade do consumidor}

Dentro do CDC, não se deve confundir a vulnerabilidade, princípio amplo e irrestrito, com hipossuficiência - debilidade processual que permite ao magistrado inverter o ônus da prova em favor do consumidor. No senso comum, podem ser utilizadas perfeitamente como palavras sinônimas, mas juridicamente, especificamente aos olhos da Lei n. ${ }^{\circ}$ 8.078/90, não.

A hipossuficiência é uma consequência desta debilidade do consumidor e deve ser interpretada como um fruto normativo e jurídico em virtude da fragilidade do consumidor que norteia sua proteção legal (NISHIYAMA e DENSA, 2011). 
A hipossuficiência é terminologia do direito social (ou do trabalho) e remete para a idéia de pobreza econômica, notadamente no acesso aos conhecimentos técnicos nas relações consumeristas. Nas demandas judiciais decorrentes destas relações, vale a facilitação da defesa, embora o consumidor possa ter condições ou não da produção de prova no processo. Em outras palavras, ele é vulnerável mas pode ou não ser hipossuficiente (ALMEIDA, 2008).

Neste norte, a vulnerabilidade é um traço universal de todos os consumidores, ao passo em que a hipossuficiência é uma marca pessoal, isto é, limitada a alguns consumidores, o que legitima um tratamento processual diferenciado no CDC. Assim, a hipossuficiência pode ser econômica, por exemplo, por dificuldades financeiras para pagar um perito e assim provar o seu direito em juízo, ou processual, porque não é detentor de conhecimento técnico para fazer prova do seu direito em contenda judicial (EFING, 2011).

Assim a hipossuficiência passa a ser um requisito para permitir que o consumidor não precise ter condições processuais de provar o seu direito, concedido deste modo pelo magistrado, que no caso concreto analisará a necessidade desta inversão. De sorte que a hipossuficiência fica caracterizada como a vulnerabilidade processual, o que nós leva a concluir que todo o consumidor é vulnerável, mas nem todo vulnerável é hipossuficiente, porque, apesar de ser vulnerável, numa demanda judicial ele pode ter condições de provar o direito frente o fornecedor.

\section{A hipervulnerabilidade (ou vulnerabilidade agravada) dos consumidores: previsão constitucional e a contribuição da jurisprudência para o seu alcance. Os casos de consumidores hipervulneráveis em razão da idade e de doença}

Apesar da ampla e irrestrita presunção de vulnerabilidade do consumidor, fixada no CDC, reconhecida pela necessidade de atuação Estatal em sua defesa e dos argumentos aqui expostos, a doutrina e a jurisprudência (MARQUES, 2014) passaram a admitir e a debater sobre a necessidade de enxergar segmentos de consumidores com vulnerabilidade maior do que a vulnerabilidade habitualmente decorrente do mercado de consumo. Enxerga-se que determinados grupos de consumidores, identificados por características especiais que os tornem mais fragilizados - ou potencialmente fragilizados -, necessitam de uma maior proteção, em razão desta debilidade acrescida, que pode ser temporária ou contínua. 
[...] a jurisprudência desenvolveu a noção de hipervulnerabildiade como um corolário positivo da proibição de discriminação logo do princípio da igualdade (um dever ser) e mandamento de pleno desenvolvimento da personalidade, diretamente ligada, pois, a nossa visão de dignidade da pessoa humana (tratamento equitativo e digno da pessoa humana). (MARQUES, 2014, p. 357).

A esta condição particular de vulnerabilidade chamamos de Hipervulnerabilidade ou Vulnerabilidade em Potencial ou Vulnerabilidade Agravada.

[...] que define a hipervulnerabilidade como "a situação social fática e objetiva de agravamento da vulnerabilidade da pessoa física consumidora, por circunstâncias pessoais aparentes ou conhecidas do fornecedor, como sua idade reduzida (assim o caso da comida para bebes ou da publicidade para crianças) ou sua idade alentada (assim os cuidados especiais com os idosos, no Código em diálogo com o Estatuto do Idoso, e a publicidade de crédito para idosos) ou a situação de dente (assim o caso do glúten e as informações na bula de remédios). (MARQUES, 2014, p. 357).

Por sua vez, esta determina um regime de tutela também particular que se nutre da situação real do consumidor, não sendo possível alcançar uma decisão sem antes ponderar as circunstâncias concretas do conflito a ser dirimido (NEGREIROS, 2002).

Como ressaltam os autores do anteprojeto do Código de Defesa do Consumidor, na palavra de Antônio Herman de V. Benjamin (2007, p. 381):

“[...] entre todos os que são vulneráveis, há outros cuja vulnerabilidade é superior à média. São os consumidores ignorantes e de pouco conhecimento, de idade pequena ou avançada, de saúde frágil, bem como aqueles cuja posição social não lhes permite avaliar com adequação o produto ou serviço que são adquirindo".

Não há como negar que há diferenças entre os consumidores e, para o nosso tema em específico, é necessária a compreensão de que tratamos de consumidores especialmente vulneráveis, isto é, com uma individualidade considerada, identificados no direito do consumidor brasileiro como consumidores hipervulneráveis e, por conseguinte, não há como não reconhecer a sua relevância jurídica.

A doutrina reforça que há situações reais de consumidores que necessitam de uma tutela específica, pois, na condição de consumidores são diferentes e apresentam uma maior fragilidade se comparados a outros consumidores (Marques, 2014).

\section{A vulnerabilidade agravada ou hipervulnerabilidade tem justificativa} Constitucional, por força do princípio da dignidade da pessoa humana - especificamente as crianças, os adolescentes, os portadores de deficiências e os idosos -, aplicando-o como solução para a tutela de pessoa consumidora no negócio jurídico em face do mínimo existencial, uma vez que o citado princípio "institui cláusula geral de tutela da dignidade da 
pessoa humana, impondo reconhecimento e influência de interesses não patrimoniais sobre relações privadas" (PINHEIRO e DETROZ, 2012, p. 128).

Podemos indicar situações que demandam a atenção especial do legislador e dos julgadores para que a dignidade da pessoa humana dos especiais consumidores seja mantida, como é o caso dos doentes, os analfabetos, dentre outros.

O facto é que há visivelmente uma demanda jurídica de aplicação da tutela destes consumidores, para assim promover-lhes garantias suplementares além daquelas já constantes da norma e do ordenamento jurídico.

As situações reais a seguir expostas são os primeiros passos desta análise e identificação das situações práticas de vulnerabilidade agravada ou hipervulnerabilidade, de modo que, a princípio, caberá à doutrina e à jurisprudência, na análise caso a caso, verificar a necessidade de proteção destes consumidores em maior grau de debilidade.

Consideramos que o avanço das discussões sobre este tema poderão impulsionar o legislador a avaliar a necessidade de elaboração de dispositivos legais mais específicos para a eficácia de uma especial proteção destes consumidores.

Neste trabalho, limitar-nos-emos na análise da doutrina e da jurisprudência. Aliada à contribuição da jurisprudência para identificação das situações em que os consumidores apresentam-se em condição de fragilidade agravada, a doutrina brasileira realiza um debate valoroso para o estudo deste facto jurídico de premente atenção.

\subsection{Hipervulnerabilidade (ou vulnerabilidade agravada) do consumidor criança}

No direito brasileiro, a proteção da criança encontra fundamento constitucional no artigo 227 da Constituição da República (MARQUES e MIRAGEM, 2012). Extrai-se do texto constitucional que a vulnerabilidade da criança detém um estado de fragilidade a priori, e deve ser considerado que a sua faixa etária é indicativa de facilidade de ser ferido ou ser vítima facilmente (MARQUES e MIRAGEM, 2012).

Neste sentido, Bruno Miragem (2015) entende que a vulnerabilidade da criança é reconhecida universalmente através da Declaração dos Direitos da Criança adotada pela Assembléia das Nações Unidas que prevê a proteção e os cuidados especiais às crianças em decorrência da sua falta de maturidade física e intelectual.

Segundo a Convenção de Direitos da ONU, podemos considerar criança como ser humano desde o seu nascimento até aos 18 anos, abarcando dentro desta faixa etária os 
adolescentes que, segundo os instrumentos internacionais, são adolescentes aqueles que tenham entre 12 a 18 anos de idade (MARQUES e MIRAGEM, 2012).

Reconheçamos que a construção da condição de criança consumidora na pós modernidade é marcada pela intensidade da participação dos infantes nas compras da família. Nos dias atuais, os genitores dispõe de tão pouco tempo para estarem ao lado dos filhos que ir às compras, mesmo sendo compras domésticas, é um momento de laser para a família, o que permite a introdução das crianças no mercado de consumo, sujeitando-as aos ataques publicitários e à variedade de produtos ofertada a este segmento dos consumidores (FERNANDÉZ, 2013).

As crianças exercem um "poder” decisório nas decisões de compra da família, em virtude da vulnerabilidade típica destes pequenos consumidores frente às estratégias de marketing empregadas pelos profissionais. Neste sentido, é dedutivo afirmar que se há uma influência sobre os adultos, mais facilmente haverá sobre as crianças, uma vez que o estágio da vida em que se encontram não tem a maturidade intelectual completa para sopesar determinados factores que envolvem os riscos e benefícios do negócio. Daí é possível, também, perceber que a vulnerabilidade destes consumidores está agravada em comparação à vulnerabilidade do consumidor adulto, considerando-os, assim, hipervulneráveis.

Sabemos que não são apenas as crianças os sujeitos que mereceram proteção acrescida
em matéria de práticas comerciais desleais, todavia, a atenção que estas merecem dos
profissionais e a vontade que estes têm em conseguir a sua atenção coloca-as em
destacado lugar. Na actual sociedade de consumo a criança foi elevada ao status de
cliente, é actualmente vista pelos profissionais como ocupando um lugar privilegiado,
de alguém que, com muita exigência compra, gasta e consome. (RODRIGUES, 2008,
p. 15).

Por não ser objeto de nossa investigação, em relação ao aprofundamento da vulnerabilidade especial das crianças, podemos mencionar com brevidade algumas situações em que a dita vulnerabilidade floresce. Por exemplo, diante dos riscos do desenvolvimento por consequência do uso precoce de aparelhos de telemóveis que, segundo estudos, são causadores de enfermidades nos ouvidos e no cérebro, recomendado o uso somente a partir dos 13 anos de idade.

Outro exemplo pode ser o da fragilidade dos ditos consumidores diante dos fornecedores de comidas e bebidas que não são saudáveis, que não poupam esforços publicitários para divulgação dos seus produtos, esquecendo-se do público infante suscetível de fácil convencimento e poder de influência junto aos pais. Tratando-se de publicidade, este 
é o meio que decididamente contribui para orientar a escolha destes consumidores para aquisição do produto. Hoje, esta publicidade é fartamente veiculada na televisão, cinema, rádio, internet, livros escolhas e embalagens de produtos, sendo capaz de convencer crianças e pais que também têm um papel relevante nesta relação criança e profissional (BERTONCELLO, 2013).

\subsection{Hipervulnerabilidade (ou vulnerabilidade agravada) do consumidor idoso}

No direito brasileiro, a proteção do idoso também encontra respaldo no texto constitucional de 1988, no artigo 230, caput, ao dispor que "a família, a sociedade e o Estado têm o dever de amparar as pessoas idosas, assegurando sua participação na comunidade, defendendo sua dignidade e bem-estar e garantindo-lhes o direito a vida" (GRAEFF, 2013, p. $67)$.

Dentro desta tutela especial, apesar de entender-se que há incontestável necessidade de proteção diferenciada, não há qualquer definição em texto normativo de quem seria consumidor idoso, de modo que esta será alcançada a partir da fusão de dois conceitos: consumidor e idoso. Assim, pelo conceito de consumidor - abordado neste trabalho - e pelo conceito de idoso ${ }^{4}$, podemos dizer que se trata de qualquer pessoa com idade igual ou superior a 60 anos que adquire ou utiliza produto ou serviço como destinatário final (GRAEFF, 2013).

Bruno Miragem enfatiza que a vulnerabilidade do consumidor idoso é demonstrada a partir de dois aspectos principais: a) a diminuição ou perda de determinadas aptidões físicas ou intelectuais que o torna mais suscetível e débil em relação a atuação negocial dos fornecedores; b) a necessidade e catividade em relação a determinados produtos ou serviços no mercado de consumo que a coloca numa relação de dependência em relação aos seus fornecedores (MIRAGEM, 2015).

Quanto ao primeiro aspecto, a fragilidade provocada pela diminuição da condição intelectual provocada pelo envelhecimento do organismo como um todo, retiram-lhe o discernimento e a ponderação necessárias para analisar determinados factores essenciais diante dos riscos e benefícios do negócio. Em relação ao segundo, é evidente que uma maior necessidade de produtos e serviços do consumidor idoso faz presumir que o eventual

\footnotetext{
4 Segundo a Política nacional do Idoso e do Estatuto do Idoso, a pessoa idosa é aquela com 60 ou mais anos de idade (respectivamente, art. $2^{\circ}$ da lei $8842 / 1994$ e art. $1^{\circ}$ da Lei $10.471 / 2003$ ).
} 
inadimplemento por parte do fornecedor dê causa a danos mais graves do que seriam de se indicar aos consumidores em geral (MIRAGEM, 2015).

Os consumidores idosos demandam proteção mais intensa, em razão da sua clara hipervulnerabilidade ou vulnerabilidade agravada e melhor proteção do Estado para algumas formas de contratação ${ }^{5}$ em que a debilidade provocada pela idade prejudica o seu discernimento na tomada da decisão de celebração ou não do pacto negocial. A atenção do Estado e da sociedade na defesa é tão necessária que o impulso constitucional na proteção e atenção à população idosa repercutiu-se na elaboração da Lei n. ${ }^{\circ}$ 10.741/2003 - Estatuto do Idoso (SCHMITT, 2009).

O processo evolutivo na construção de um regime especialmente concebido para a proteção eficaz do consumidor idoso ganha reforço no projeto de lei $283 / 212^{6}$ que, caso seja aprovado, alterará o Código de Defesa do Consumidor para aperfeiçoar a disciplina do crédito ao consumidor e prevê a inclusão do termo idoso e de direitos expressamente reservados a ele na lei brasileira (GRAEFF, 2013).

Dentro do ordenamento jurídico brasileiro, a necessidade de visualizar a fragilidade do consumidor idoso e, principalmente, buscar meios de protegê-lo, parece-nos que alcança mais autores e chega aos juízes de modo a fazê-los perceber que em muitas situações é necessário cautela, análise e percepção nas suas decisões, possibilitando-os enxergar a debilidade destes consumidores nos casos concretos que passam a julgar. Neste sentido, há decisões que avaliaram a posição do consumidor idoso como sendo de fragilidade, de modo que é possível identificar na jurisprudência uma hipervulnerabilidade do consumidor idoso.

O Supremo Tribunal Federal ${ }^{7}$ reconheceu a vulnerabilidade do consumidor idoso na Repercussão Geral no recurso Extraordinário n. ${ }^{\circ}$ 630.852/RS, julgado em 2004, sob relatoria da Ministra Ellen Gracie, que afirma que “o idoso é um consumidor duplamente vulnerável,

\footnotetext{
${ }^{5}$ Como exemplo podemos citar os contratos de planos e de seguros privados de saúde e alinha de financiamento designada de "crédito consignados para aposentados".

${ }^{6}$ O projeto de lei do Senado Federal n. ${ }^{\circ}$ 283/2012 prevê a expressão do termo idoso e direitos a esse sujeito reservados: “Art. 54-B, $\varsigma^{\circ}$, IV - ocultar, por qualquer forma, os ônus e riscos da contratação do crédito, dificultar sua compreensão ou estimular o endividamento do consumidor, em especial se idoso ou adolescente; Art. 54-F, IV - assediar ou pressionar o consumidor, principalmente, se idoso, analfabeto, doente ou em estado de vulnerabilidade agravada, para contratar o fornecimento de produto, serviço ou crédito, em especial à distância, por meio eletrônico ou por telefone, ou se envolver prêmio". Disponível em: http:// www.senado.gov.br/atividade/materia/detalhes.asp?p_cod_mate=106773. Acesso em 12 de maio de 2015.

${ }^{7}$ Cfr. Acórdão do Supremo Tribunal Federal em Repercussão Geral no Recurso Extraordinário 630.852/RS, sob relatoria da Ministra Ellen Gracie, publicado em 07 de abril de 2011. Disponível em http://www.stf.jus.br/portal/ inteiroTeor/pesquisarInteiroTeor.asp\#resultado. Acesso em 12 de maio de 2015.
} 
necessitando de tutela diferenciada e reforçada", ao pontuar que "dentre os novos sujeitos de direito que o mundo pós-moderno identifica, a Constituição Federal de 1988 concede uma proteção especial a dois deles, que interessa ao tema planos de saúde: consumidor e o idoso".

\subsection{Hipervulnerabilidade (ou vulnerabilidade agravada) do consumidor doente}

A condição de enfermidade é aceite pela doutrina como factor capaz de fragilizar o consumidor, impedindo-o ou dificultando-o de exercer a sua liberdade de escolha em relação contratual com os fornecedores, aproveitando-se deste modo da sua debilidade emocional que a enfermidade pode trazer. A enfermidade, mesmo que breve ou por tempo prolongado, incurável ou não, pode ser um factor considerável a influenciar o consumidor no seu poder de decisão, retirando-lhe a possibilidade de livre escolha dos itens de consumo. Em outros termos, a doença tem a possibilidade de alterar psicologicamente o consumidor, levando-o a tomar decisões equivocadas ou precipitadas e deixando-o a mercê das provocações do mercado ${ }^{8}$.

Para o bem da proteção dos consumidores doentes no Superior Tribunal de Justiça, no julgado pelo Ministro Herman Benjamin, em voto proferido no Recurso Especial n. ${ }^{\circ}$ 586.316/MG, em que ele identificou os consumidores hipervulneráveis, no caso os celíacos9.

O relator explica que o organismo das pessoas com a doença celíaca sofre intolerância ao glutén, que nada mais é do que um grupo de proteínas encontradas em certos grãos. A doença é uma enfermidade crônica no aparelho digestivo e pode causar perda de peso, hemorragias internas, dentre outros males. Afirma o Ministro haver um número expressivo de pessoas que sofrem de doença celíaca.

No acordão Herman Benjamin aponta quatro questões: a) o caráter exaustivo da lei n. ${ }^{\circ} 10.674 / 03$ de modo a afastar a aplicação do dever de informação presente do artigo 31 do CDC; b) o campo de aplicação material do artigo 31 com análise das várias modalidades do

\footnotetext{
${ }^{8}$ Cfr. Claudia Lima Marques e Bruno Miragem. O novo direito privado e a proteção dos vulneráveis..., cit., pp. 188 e 189, que entende que “(...) a hipervulnerabilidade seria a situação social fática e objetiva de agravamento da vulnerabilidade da pessoa física consumidora, por circunstâncias pessoais aparentes ou conhecidas do fornecedor, como (...) sua situação de doente. (...) Em outras palavras, enquanto a vulnerabilidade 'geral' do art. $4^{\circ}$, I se presume e é inerente a todos os consumidores (em especial tendo em vista a sua posição nos contratos, tema desta obra), a hipervulnerabilidade seria inerente e "especial" à situação pessoal de um consumidor, seja permanente (prodigalidade, incapacidade, deficiência física ou mental) ou temporária (doença, gravidez, analfabetismo, idade)".

${ }^{9}$ Cfr. Acórdão do Superior Tribunal de Justiça em Recurso Especial n. ${ }^{\circ}$ 586.316/MG, sob relatoria do Min. ${ }^{\circ}$ Herman Benjamin. Disponível em https://ww2.stj.jus.br/processo/revista/documento/mediado/? componente $=A T C \&$ sequencial $=2893505 \&$ num_registro $=200301612085 \&$ data $=20090319 \&$ tipo $=51 \&$ formato $=P$ DF. Acesso em 17 de março de 2015.
} 
dever de informação; c) a suficiência dos dizeres “contém glutén”, para cumprimento das exigências do artigo 31 do CDC, considerando os altos riscos à saúde e segurança de um número expressivo de consumidores, que estariam assegurados com uma advertência mais precisa possível; d) o campo subjetivo do artigo 31 referido que permite salvaguardar grupos de consumidores hipervulneráveis.

Para o Ministro (2003, p. 8): “o dever de informação, previsto no CDC, tem finalidade inegável, óbvia até: informar o consumidor sobre o que é relevante, da melhor e mais completa forma possível”. Dessa forma o dever de informação atinge um comportamento positivo, pois, como relata, o CDC não aceita que o silêncio equivalha à informação. Assim, o comportamento positivo necessita de uma informação prestada de forma completa no sentido jurídico e prático. A informação completa no sentido jurídico é aquela informação adequada, ou seja, verdadeira, clara, gratuita e útil, sem a diluição de informações efetivamente relevantes.

Neste sentido, o relator (2003, p. 9) frisa que os fabricantes pretendiam omitir intencionalmente a frase "contém glutén: a existência do glutén é prejudicial a saúde dos doentes celíacos". Omitir a referência à prejudicialidade do glutén faz com que a informação seja apenas um conteúdo e não uma advertência para os fins a que se propõe, sendo a informação referida insuficiente para a sua finalidade, de modo que educar pelo rotulo da embalagem é menos traumático e socialmente louvável.

A decisão reconhece a hipervulnerabilidade quando o relator $(2003$, p. 9) afirma que “o Código de Defesa do Consumidor protege todos os consumidores, mas não é insensível à realidade da vida e do mercado, vale dizer, não desconhece que há consumidores e consumidores". Complementa quando fixa que "existem aqueles que, no vocabulário da disciplina, são denominados de hipervulneráveis".

Dessa forma, Herman Benjamin salienta que os agentes econômicos devem atentar para as peculiaridades de saúde e segurança dos consumidores. Se os riscos de um produto ou serviços são gritantes e massificados, compete à administração pública controlá-los. Trata-se da opção de intervenção na ordem econômica quando se está diante de um grupo e não da generalidade dos consumidores. Complementa o Ministro Benjamin, 2003, p.10: 
pretexto de que são estranhos à generalidade das pessoas, é pela via de uma lei que na origem pretendia-lhes dar especial tutela, elevar a raiz quadrada a discriminação.

Conclui o Relator do voto recomendando que os grupos especiais de consumidores, por uma ou outra razão, precisam da interpretação do artigo 31 do CDC para que a sua tutela seja garantida.

O Ministro acolhe a tese da hipervulnerabilidade quando do julgamento da suficiência ou não dos dizeres "contém glúten" nas embalagens de alimentos industrializados considerando os riscos para a saúde e a segurança de consumidores. Desse modo, o julgador recorre a argumentos pautados na necessidade de proteção da minoria da população, tendo necessidade de proteção por parte do legislador para reequilibrar a relação. Destaca que há a necessidade do Estado Democrático de Direito de assegurar a igualdade material para que certos grupos de consumidores hipervulneráveis encontrem tutela especial ${ }^{10}$.

\section{Conclusão}

Diante do exposto concluímos que é cediço que o desequilíbrio contratual permanente nas relações de consumo demanda proteção legal e Estatal, por mais evoluído que seja o ordenamento jurídico - detenção de instrumentos jurídicos de protecção nesta relação -, dificilmente evitará que os consumidores sejam lesados ${ }^{11}$. O que liga os sujeitos no mercado são os seus interesses econômicos, consumidores em busca de produtos ou serviços oferecidos por empresas que apenas se preocupam em vender a produção.

Assim, se tratando de interesses econômicos, o poder de atuação no mercado põe em larga vantagem a sobreposição dos interesses das empresas.

A defesa dos interesses dos consumidores pede uma frequente atenção do legislador na busca de um "elevado nível de proteção dos consumidores" - utilizando uma expressão presente nas normas da União Europeia, mas que também se aplica ao Brasil, bem como outros sistemas jurídicos e, ainda, uma política de proteção eficaz com suporte na percepção de que existem consumidores e consumidores, isto é, por mais gerais e abstractas que sejam

\footnotetext{
${ }^{10}$ Cfr. Acórdão do Superior Tribunal de Justiça em Recurso Especial n. ${ }^{\circ}$ 586.316/MG, sob relatoria do Min. ${ }^{\circ}$ Herman Benjamin. Disponível em https://ww2.stj.jus.br/processo/revista/documento/mediado/? componente $=$ ATC \&sequencial $=2893505 \&$ num registro $=200301612085 \&$ data $=20090319 \&$ tipo $=51 \&$ formato $=P$ DF. Acesso em 17 de março de 2015.

11 Entendemos que paralelamente a evolução do direito do consumidor está o melhoramento das técnicas de marketing, publicidade e práticas comerciais fruto da sociedade de consumo que permanecerá sempre a atenta, primeiramente, a venda, e por via legal, em segundo plano, "voltada" ao consumidor.
} 
as normas - e, até mesmo, por mais específicas que sejam - elas podem não dar a proteção que se espera.

Além disso, a vulnerabilidade habitual sofrendo influência de aspectos pessoais em determinados grupos de consumidores e sofre uma variação. Isto é, torna-se uma vulnerabilidade maior, aumentada, de maneira que não nos resta dúvida do reconhecimento do que preferimos tratar de "especial vulnerabilidade".

De sorte que, o que os diferencia não é somente a expressão usada para identificálos, mas, principalmente, o nível de reconhecimento da necessidade de proteção também especial. E quando falamos de proteção, não pretendemos uma total mudança no sistema jurídico dos consumidores, mas apenas, e até mesmo na menor das hipóteses, uma interpretação diferenciada em relação aos próprios instrumentos legais já existentes.

Com efeito, percebemos que esta maior fragilidade, sinalizada pelos ordenamentos jurídicos em análise, alcança fundamento na própria proteção dos consumidores - o que é natural -, mas, principalmente, pela preservação da dignidade humana deste grupo de consumidores e pela garantia de livre exercício dos seus direitos de personalidade na posição de contratante no mercado de consumo.

É assim que nesta pesquisa a nossa atenção esteve relacionada à vulnerabilidade dos consumidores no mercado, ao salientarmos e entendermos que alguns grupos de consumidores demandam maior proteção, posto que já se encontram reconhecidos nos sistemas jurídicos que comparamos, porém, não devidamente protegidos.

\section{Referências}

ALMEIDA, João Batista de. A proteção jurídica do consumidor. $6^{\mathrm{a}}$ ed. São Paulo: Saraiva, 2008.

BENJAMIN, Antônio Herman V.; MARQUES, Claudia Lima; BESSA, Leonardo Roscoe. Manual de direito do consumidor. $2^{\text {a }}$ ed. RT: São Paulo, 2008.

BERTONCELLO, Káren Rick Danilevicz. Os efeitos da publicidade na "vulnerabilidade agravada": como proteger as crianças consumidoras? Revista de Direito do Consumidor, n. ${ }^{\circ}$ 90. São Paulo: Editora Revista dos Tribunais, pp. 69 a 90, 2013.

BRASIL. Congresso. Senado. Projeto de lei n. ${ }^{\mathbf{2}}$ 283, de 2012. Tem objetivo de alterar a Lei $\mathrm{n}^{\circ} 8.078$, de 11 de setembro de 1990, para aperfeiçoar a disciplina do crédito ao consumidor e 
dispor sobre a prevenção do superendividamento. Disponível em: 〈http://www.senado.gov.br/ atividade/materia/detalhes.asp?p_cod_mate=106773>. Acesso em 12 de maio de 2015.

BRASIL. Acórdão do Supremo Tribunal Federal em Repercussão Geral no Recurso Extraordinário 630.852/RS, sob relatoria da Ministra Ellen Gracie, publicado em 07 de abril de 2011. Disponível em: < http://redir.stf.jus.br/paginadorpub/paginador.jsp? docTP=AC\&docID=623586> . Acesso em 12 de maio de 2015.

BRASIL. Superior Tribunal de Justiça. Recurso Especial n..$^{\mathbf{5}}$ 586.316/MG, sob relatoria do Min. ${ }^{\circ}$ Herman Benjamin. Revista Eletrônica de Jurisprudência do STJ. Disponível em: $<$ https://ww2.stj.jus.br/processo/revista/documento/mediado/? $\underline{\text { componente }=A T C \& \text { sequencial }=2893505 \& \text { num_registro }=200301612085 \& \text { data }=20090319 \& \mathrm{ti}}$ po=51\&formato=PDF $>$. Acesso em 17 de março de 2015.

CORDEIRO, António Menezes. Tratado de direito civil português. Vol. I, Tomo I, $3^{\mathrm{a}}$ ed., Coimbra: Almedina, 2005

DERANI, Cristiane. Política nacional das relações de consumo e o código de defesa do consumidor. Revista de Direito do Consumidor, n. ${ }^{\circ}$ 29, 1999.

EFING, Antônio Carlos. Direito do consumo e direito do consumidor: reflexões oportunas. Revista Luso -Brasileira de Direito do Consumo, n. ${ }^{\circ} 1$. Curitiba: Editora Bonijuris LTDA e J.M. Editora e Livraria LTDA, pp. 103 a 120, 2011.

FERNANDÉZ, Marta Morillas. La protección jurídica de los menores ante la plubicidad: una visión comuún de España y Portugal. Revista Luso Brasileira de Direito do Consumo, n. ${ }^{\circ}$ 10. Curitiba: Editora Bonijuris LTDA e J.M. Editora e Livraria LTDA, 2013.

FILOMENO, José Geraldo Brito. Manual de direitos do consumidor. $10^{a}$ ed., São Paulo: Atlas, 2010.

GRAEFF, Bibiana. Direitos do consumidor idoso no Brasil. Revista de direito do Consumidor, n. ${ }^{\circ}$ 86. São Paulo: Editora Revista dos Tribunais, 2013.

Cristiano Heineck Schmitt. A hipervulnerabilidade do consumidor idoso. Revista de direito do consumidor, n. ${ }^{\circ}$ 70. São Paulo: Editora Revista dos Tribunais, pp. 139 a 171, 2009.

GIANCOLI, Bruno Pandori e ARAUJO JÚNIOR, Marco Antonio. Direito do Consumidor. $3^{\text {a }}$ ed. São Paulo: RT, 2012.

GRIONOVER, Ada Pelegrini Grinover... [et al.]. Código de defesa do consumidor comentado pelos autores do anteprojeto. $9^{\text {a }}$ ed. Forense: Rio de Janeiro: 2007.

LORENZETTI, Ricardo. Fundamentos de direito privado apud Marília Zanchet. A vulnerabilidade e a proteção dos mais fracos no MERCOSUL. Cadernos do programa de 
pós-graduação Direito/UFRGS. n. 3 (2005). Disponível em: <http://seer.ufrgs.br/index.php/ ppgdir/article/view/50235/31381>. Acesso em 06 de maio de 2015

MARQUES, Claudia Lima. Algumas considerações sobre a pessoa no mercado e a proteção dos vulneráveis no direito privado brasileiro. Direito privado, constituição e fronteiras: encontro da associação luso-alemã de juristas no Brasil. $2^{\mathrm{a}}$ ed., São Paulo: São Paulo: Revista dos Tribunais, 2014, pp. 287-332.

MARQUES, Claudia Lima e MIRAGEM, Bruno Miragem. O novo direito privado e a proteção dos vulneráveis. São Paulo: RT, 2012.

MARQUES, Claudia Lima. Contratos no Código de Defesa do Consumidor: o novo regime das relações contratuais. $6^{\text {a }}$ ed. São Paulo: Editora Revista dos Tribunais, 2014.

MIRAGEM, Bruno. Curso de direito do consumidor. $5^{\text {a }}$ ed. São Paulo: Revista dos Tribunais, 2015.

MORAES, Valério Dal Pai. Código de Defesa do Consumidor: o princípio da vulnerabilidade no contrato, na publicidade e nas demais práticas comerciais. Porto Alegre: Síntese, 2009.

NEGREIROS, Teresa. Teoria do contrato: paradigma contratual. São Paulo: Renovar, 2002.

NISHIYAMA, Adolfo Mamoru e DENSA, Roberto. A proteção dos consumidores hipervulneráveis: os portadores de deficiência, os idosos e as crianças e os adolescentes. in: Claudia Lima Marques; Bruno Miragem. Doutrinas Essenciais Direito do Consumidor: fundamentos do direito do consumidor - (Coleção doutrinas essenciais, v.2). São Paulo: Editora Revista dos Tribunais, pp. 431 a 461, 2011.

NUNES, Rizzatto. Curso de direito do consumidor. $7^{a}$ ed. rev. e atual. São Paulo: Saraiva, 2012.

OLIVEIRA, James Eduardo. Código de defesa do consumidor: anotado e comentado. 5 ed. São Paulo: Atlas, 2009.

PASQUALOTTO, Adalberto. Defesa do consumidor. In: Claudia Lima Marques; Bruno Miragem. Doutrinas Essenciais Direito do Consumidor: fundamentos do direito do consumidor - (Coleção doutrinas essenciais, v.1), São Paulo: Editora Revista dos Tribunais, 2011.

PINHEIRO, Rosalice Fidalgo e DETROZ, Derlaune. A hipervulnerabilidade e os direitos fundamentais do consumidor idoso no direito brasileiro. RDPC, n. ${ }^{\circ}$ 71, pp. 109 a 148, 2012. 
RODRIGUES, Hélio T. Rigor. A Proteção dos consumidores Vulneráveis nas práticas comerciais desleais: Análise da Directiva 2005/29/CE e do Decreto-Lei 57/2008. RPDC, n. ${ }^{\circ}$ 556, 2008. Disponível em: <http://vlex.com/vid/vulneraveis-comerciais-desleaisanalise-219407433>. Acesso em 25 de outubro de 2014

TARTUCE, Flávio e NEVES, Daniel Amorim Assumpção. Manual de direito do consumidor: direito material e processual. Rio de Janeiro: Forense, São Paulo: Método, 2012. 